\title{
The Interlanguage Rhythm of Algerian EFL Undergraduates
}

\begin{abstract}
:
This paper is an attempt to classify the rhythm of the interlanguage produced by third year Algerian EFL students at Constantine 1 University. The nature of speech rhythm classes has been hotly debated as to whether it should be conceived as a discrete stress-timed vs. syllable-timed dichotomy or as a continuum. The rhythm metrics measured in this study i.e. $\% \mathrm{~V}$ and $\Delta \mathrm{C}$, yield that the informants' speech rhythm is rather 'intermediate', merging a stress-timed $\Delta \mathrm{C}$ and a syllabletimed $\% \mathrm{~V}$. Accordingly, the results obtained support those who believe that crosslinguistic interference in the area of phonology touches not only segments but also speech rhythm.

Key Words: Interlanguage rhythm, dichotomy vs. continuum, rhythm metrics: $\% \mathrm{~V}$ and $\Delta \mathrm{C}$.
\end{abstract}

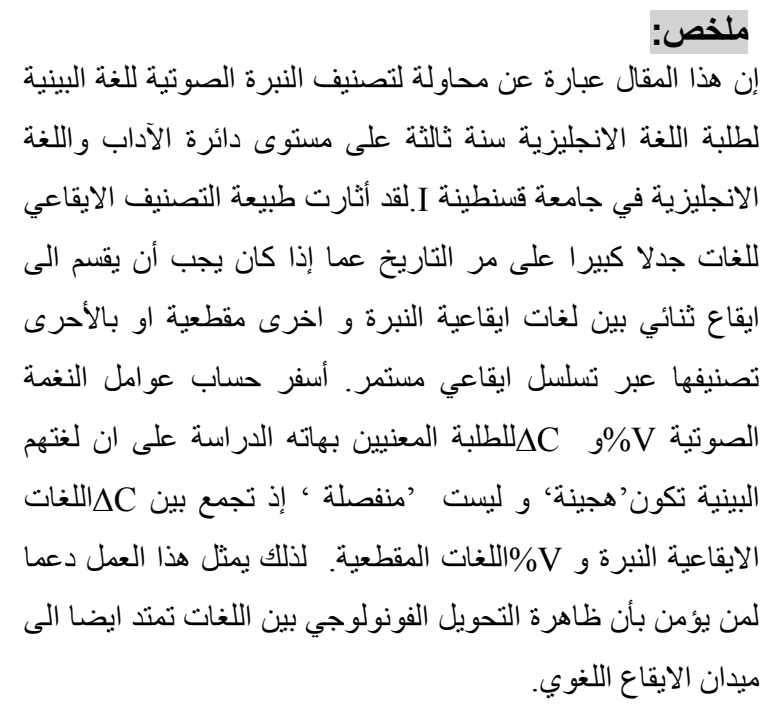

The rhythmic category of the English performance of Arab learners should not be regarded as an inevitable result to the fact that both languages involved, learners' mother tongue (dialectal Arabic) and the language being learnt (English), are grouped together in one rhythmic class namely stress-timed. Measuring speech rhythm of a given language takes into account its phonological properties that are proven to set apart languages rhythmically. In this paper, we measure the rhythmic performance of 
26 Algerian learners of English as an attempt to classify it into either a discrete rhythmic class or rather in a continuum, knowing that French, a typical syllable-timed language, is their first foreign language while English is the second.

\section{History of Speech Rhythm Typology}

It is widely accepted that the human ear has a natural tendency to distinguish between different sound patterns among different languages just like the perception of different ticks of the clock or any other physical activity that causes some sort of alternation between two movements. French and English, by way of example, are rarely said to belong to the same speech pattern. Perhaps what gives this perceptive impression is the recurrence of the same element at regular intervals: stresses in English as opposed to syllables in French. Based on such a temporal organization, languages were pigeonholed as either syllable-timed or stress-timed languages (Pike 1945 and Abercrombie 1967). This line of research takes as its point of departure the work of Pike. He believes that English can reflect both rhythmic categories having each time a different rhythmic unit. According to him (1945: 34) in some languages, "the units tend to follow one another in such a way that the lapse of time between the beginning of their prominent syllables is somewhat uniform" and in other languages, "each unstressed syllable is likely to be sharp cut, with a measured beat on each one" (ibid: 35). This binary distinction, even though first noticed in one language namely English, breaks its way through to encompass all the existing languages. Accordingly, in stress-timed languages, inter-stress intervals are virtually of equal duration regardless of the number of syllables they include. However, in syllable-timed languages, syllables share more or less the same duration which makes the one of inter-stress intervals proportional to the number of syllables included.

20 years later, Abercrombie (1967) added a physiological touch to the isochronous-based typology of speech rhythm. He maintains that the driving force behind the impression of periodicity in speech rhythm resides in the contractions of breathing muscles. Simple contractions i.e. chest-pulses characterize syllable-timed languages and strong contractions i.e. stress-pulses characterize stress-timed languages (Patel, 2008). However, in the absence of empirical validation, this longstanding isochronous-based rhythmical scheme was discarded. It was strongly confuted by the majority of instrumental studies undertaken in the early 80 s to check the validity of Pike and Abercrombie's claims (to name but a few: Roach 1982, Dauer 1983, 1987,...). Roach (1982), for instance, concluded that the duration of both syllables and inter-stress intervals is proportional to the number of segments and the number of syllables respectively. Therefore, stresses and syllables are no longer considered a sine qua non of rhythm, and isochrony is thought to be a "tendency", as Beckman (in Laver, 1994) terms it, based on a "subjective perception". 
In the early $80 \mathrm{~s}$, researchers approached this line of inquiry from a phonological framework that, presumably, best accounts for the undoubted rhythmic differences proven to exist by psycholinguistics. Dauer (1983) measured the duration of inter-stress intervals of English as a stress-timed and Italian, Greek, and Spanish as syllable-timed. Following the results obtained (the duration of inter-stress intervals is more or less the same across the set of tested languages), she concluded that the different realizations of phonological properties, namely: syllable structure, vowel reduction, and salient stress across languages give a clear gestalt to the phonological word or syllable. Stress-timed languages, as opposed to syllable-timed languages, exhibit a variety of syllable structures, a system of reduced vowels, and a strong influence of stress on vowel duration and syllable prominence. Based on this ground, Dauer (1983, 1987) suggested a scalar classification of languages in a rhythm continuum instead of the usual dichotomy as those language-dependent phonological properties do not always co-occur (Polish exhibits complex syllable structure but no vowel reduction).

Few years later, the pendulum swung back to durational measurements of some acoustic signals. Ramus et al. (1999) set specific durational correlates that best fit the most important phonological criteria put by Dauer (1983), namely syllable structure and vowel reduction. They computed the duration of vocalic and intervocalic (or consonantal) intervals of an utterance and derived from both values acoustic metrics: $\% \mathrm{~V}$ (the proportion of vocalic intervals) and $\Delta \mathrm{C}$ (the standard deviation of intervocalic intervals). The rationale behind this grouping of acoustic signals is the fact that languages displaying a complex syllabic structure along with vowel reduction, i.e. stress-timed, devote more time for consonants and hence less time for vowels (the opposite is true for syllable-timed languages). It turned out that the rhythm metrics $(\% \mathrm{~V}$ and $\Delta \mathrm{C})$ bore fruit as the results obtained fit the old rhythmic classification of languages set forth by Pike (1945) and Abercrombie (1967). English, Dutch and Polish were grouped together confirming the stress-timed hypothesis while French, Spanish, Italian, and Catalan were grouped together as being syllable-timed languages. Japanese, however, was set apart from both groups admitting the existence of a third rhythmic category that is, mora-timed. In light of Ramus et al, encouraging results, rhythm metrics gave birth to a myriad number of studies, to name, those of: Ghazali et al, (2002), Barry et al, (2003), Mairano (2011), etc. Instrumentally enhanced, a set of indices: PVI (Grabe and Low (2002), Varcos (Dellwo and Wagner (2003) was introduced to complement Ramus et al. (1999) metrics. Therefore, the last decade knew a number of studies that were undertaken as an attempt to either test the reliability of the different rhythm metrics, to compare the data obtained by different metrics, or merely to classify languages rhythmically. The present article is an attempt to 
classify the interlanguage produced by 26 Algerian students of English by means of the first derived rhythm metrics i.e. $\% \mathrm{~V}$ and $\Delta \mathrm{C}$.

\section{The Study}

\subsection{Subjects}

26 third year students reading for a BA degree at the Department of Arts and English language, Constantine 1 University were involved in the present study. The choice of population is based on the fact that the BA degree is obtained after passing the third year. Therefore, students at that level are supposed to have a good command of English both in using and understanding it.

\subsection{Recording Procedure}

The data were deliberately called towards the end of the academic year 20122013 for two main reasons: first, to insure that the subjects took all the courses scheduled for the third year; second, to provide the best environment for the recording.

The subjects were gathered in one classroom and asked to read silently 'the north wind and the sun' IPA story ${ }^{(1)}$, as many times as they needed in order to get acquainted with the passage. For authenticity purposes, they were not allowed to discuss the pronunciation of the words, their meaning or engage in any communication whatsoever (including using dictionaries) that might lead to a change in their actual level of proficiency and fluency.

The recording process took place in a laboratory at the Department of Arts and English language, University of Constantine 1, and students were recorded individually. The author's laptop was the main equipment for implementing this task, and Praat was the recording software used to record the subjects' performance using a condenser microphone.

\subsection{Segmentation and Analysis Procedures}

All the 26 recorded files ( 40 to 50 seconds per each file) were segmented by the author of this study following the experimental procedures put by Ramus et al. (1999). Praat, a speech analysis software, was the tool used to tokenize the audio files as well as to segment the phonemes into $\mathrm{V}$ and $\mathrm{C}$ sequences relying on acoustic (formants, shape of spectral waveforms, etc) and audio cues. The criteria responsible for the identification of vowels and consonants adopted in this study comply with those generated by Ramus et al.:

-Formants were basically the main criterion used to mark the offset and onset of Vs and Cs but, the audio cues took precedence over in the absence of clear spectral cues.

-The phenomenon of assimilation was taken into consideration. Whenever there was no clear- cut between the offset of some words and the onset of what followed, they were merged in one phoneme if not separated by a clear pause.

-Pauses and hesitations were marked by the symbol \# and were excluded from the analysis and measurements. 
-Pre-vocalic (wind /wind/) and inter-vocalic (the one/ठəw $\mathrm{n} /$ ) glides were marked as Cs whereas post-vocalic glides (blew /blu:/-pronounced by many /bləひ/-) were marked as Vs as they were phonetically transcribed as V sounds in the first place.

-The post-vocalic / $\mathrm{r} /$ was labelled a $\mathrm{C}$ sound whenever pronounced.

- Unlike the burst phase of plosives that is clearly observed on spectrograms, neither visual nor audio cues can help in determining how long the hold phase of initial-voiceless plosives ( $\mathrm{p}, \mathrm{t}, \mathrm{k}$ ) lasts as it is represented by silence. Therefore, that phase was not taken into consideration when analysing the data.

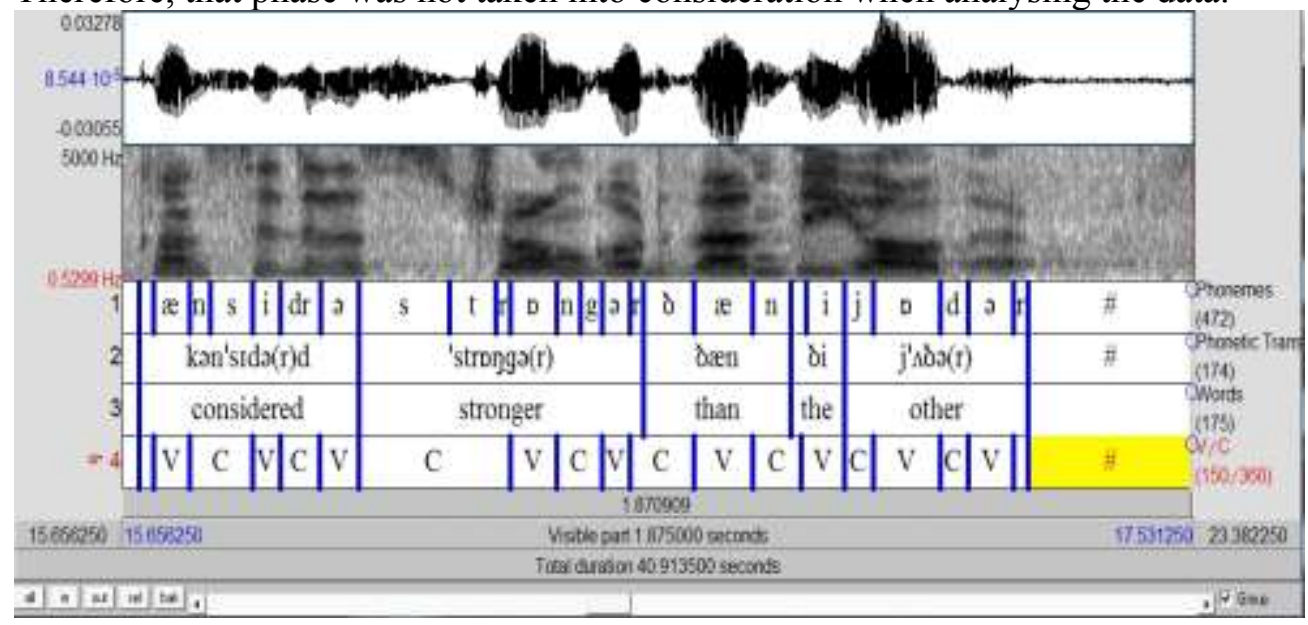

Figure1. Segmentation of a Speech Sample

\subsection{Measurements Procedure and Results}

The first step was to merge any string of consecutive vowels or consonants, except those separated by a pause, in the same sequence at the V/C annotation tier since the concern of the present study is to measure the proportion of vocalic and inter-vocalic intervals, not the duration of individual phonemes per se.

The second step was computing vowel quantity and consonant variance ( $\mathrm{V} \%$ and $\Delta \mathrm{C}$, respectively) using Correlatore, a software specially designed to measure different rhythm metrics.

There was no need to measure the sum of the duration of $\mathrm{V}$ and $\mathrm{C}$ sequences of each audio file since correlatore automatically subtracted pauses $(\neq)$ from the whole duration of the audio file.

After measuring $\mathrm{V} \%$ and $\Delta \mathrm{C}$ of all the 26 audio files, the mean of each metric was counted.

The following table shows the values obtained when counting $\% \mathrm{~V}$ and $\Delta \mathrm{C}$ of all the 26 audio files: 


\begin{tabular}{|c|c|c|}
\hline Subjects & \%V(Vowel Quality) & $\Delta \mathrm{C}$ (Consonant Variance) \\
\hline 1 & 45.03 & 68.77 \\
\hline 2 & 45.94 & 56.38 \\
\hline 3 & 46.88 & 62.65 \\
\hline 4 & 48.55 & 65.67 \\
\hline 5 & 43.06 & 62.62 \\
\hline 6 & 40.06 & 71.32 \\
\hline 7 & 45.21 & 67.67 \\
\hline 8 & 48.51 & 56.39 \\
\hline 9 & 47.00 & 65.62 \\
\hline 10 & 47.16 & 60.39 \\
\hline 11 & 44.61 & 68.87 \\
\hline 12 & 45.48 & 59.15 \\
\hline 13 & 42.64 & 59.30 \\
\hline 14 & 41.50 & 59.27 \\
\hline 15 & 41.45 & 66.36 \\
\hline 16 & 41.24 & 62.35 \\
\hline 17 & 44.02 & 64.00 \\
\hline 18 & 41.68 & 67.31 \\
\hline 19 & 47.49 & 61.52 \\
\hline 20 & 42.70 & 63.85 \\
\hline 21 & 49.54 & 59.40 \\
\hline 22 & 46.28 & 66.10 \\
\hline 23 & 41.37 & 63.80 \\
\hline 24 & 42.32 & 66.65 \\
\hline 25 & 46.09 & 68.33 \\
\hline 26 & 44.40 & 66.03 \\
\hline Mean & 44.62 & 63.84 \\
\hline
\end{tabular}

Table1: All informants' $\% \mathrm{~V}$ and $\Delta \mathrm{C}$ Values

The above results show the values of $\% \mathrm{~V}$ and $\Delta \mathrm{C}$ of all the participants. The proportion of vocalic intervals fall into the forties range, representing less than $50 \%$ of the overall duration of the passage recorded. However, the values of the standard deviation of the consonantal intervals display variance among the participants, ranging from 56 to 71 with the biggest proportion falling into the sixties range (19 out of $26 / 73,08 \%$ ).

\subsection{Discussion}

The obtained results show a negative correlation between $\% \mathrm{~V}$ and $\Delta \mathrm{C}$ : 44.62 and 63.84 respectively. According to Ramus et al. (1999), the rhythmic class that best fits this correlation is the stress-timed category. This latter exhibits a variation in the syllable structure which implies variability in the number of consonants included within a syllable as well as variability in the 
overall duration of individual consonants within the syllable. Lower values of $\% \mathrm{~V}$ are an inescapable result of higher $\Delta \mathrm{C}$ as the more consonants used, the fewer vowels displayed.

\subsection{1. $\Delta$ C Analysis}

What makes the informants' $\Delta \mathrm{C}$ higher is first the unrestricted retention of the $/ \mathbf{r} /$ sound in all phonological environments with almost all the participants (18 out of 26). Unlike the English /r/, which is pronounced only before vowels or intervocalically, its Arabic and French counterpart is pronounced before or after vowels except for the French $1^{\text {st }}$ group infinitive verbs. For that reason, learners tend to carry over their already acquired attitudes and pronounce the $/ \mathrm{r} /$ whenever it occurs. Interlingual transfer can be seen in words having almost the same graphological make-up in both English and French: 'north'- 'nord' and 'considered'- 'considérer' (20 and 23 erroneous instances respectively). In the majority of cases, the $/ \mathrm{r} /$ is retained and under some circumstances is substituted with a trill that is mostly used in Algerian Arabic. Intralingual transfer can, by the same token, be held responsible for the informants' faulty production; the students' obsession and pursuit of sounding American favour the pronunciation of the $/ \mathrm{r} /$ especially the trill in final

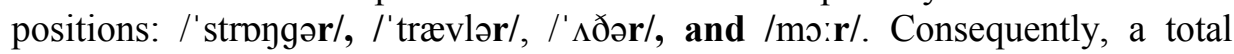
distortion of rhythm is noticed as a wrong retention of $/ \mathrm{r} /$ triggers a change in its quality and, occasionally, in the quality and quantity of the preceding vowels which are more lengthened than should be: /'trævlpr/.

\begin{tabular}{|c|c|c|c|}
\hline Word & $\begin{array}{l}\text { Informants' } \\
\text { Pronunciation }\end{array}$ & $\begin{array}{c}\text { French Possible } \\
\text { Source of } \\
\text { Transfer }\end{array}$ & $\begin{array}{c}\text { Arabic Possible } \\
\text { Source of } \\
\text { Transfer }\end{array}$ \\
\hline /no: $\theta /$ & /nว:r $\theta /$ & /пэь/ & \\
\hline /wo/ & /weər/ & - & /wæ:؟`r/ \\
\hline /'strongə/ & /'strõgər/ & - & - \\
\hline /'trævələ/ & /'trævlə/pr/ & - & - \\
\hline /wo:m/ & /wo:.Jm/ & - & /ward/ \\
\hline /'f3:st/ & /'fз:.ust/ & - & - \\
\hline /kən'sıdəd/ & /'kõsıdrəd/ & /kõsidese/ & - \\
\hline /'^ðə/ & 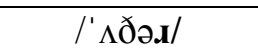 & - & - \\
\hline /ha:d/ & /ha:rd/ & - & /llard// \\
\hline /mo:/ & /mo:I/ & - & - \\
\hline
\end{tabular}

Table 2: Retention of $/ \mathrm{r} /$ sound

Second, vowel syncope or the deletion of schwa in some unstressed syllables caused the creation of consonant clusters and hence the addition to the overall duration of consonantal intervals as two resulting juxtaposed consonants, normally separated by a schwa, are gathered in the same sequence: (/'trævl(ə/p)r/ instead of /'trævala/ 4 erroneous instances per nearly each informant $23 / 26)$ and $(/ \mathrm{kə}(\tilde{\mathrm{o}} / \mathrm{a}:) \mathrm{nsidr} \partial \mathrm{d} / \mathrm{instead}$ of $/ \mathrm{kən}$ 'sidəd/ since the 
informants tend to pronounce the $/ \mathrm{r} /$ ). The following spectrogram represents the schwa deletion in /'trævələ/:

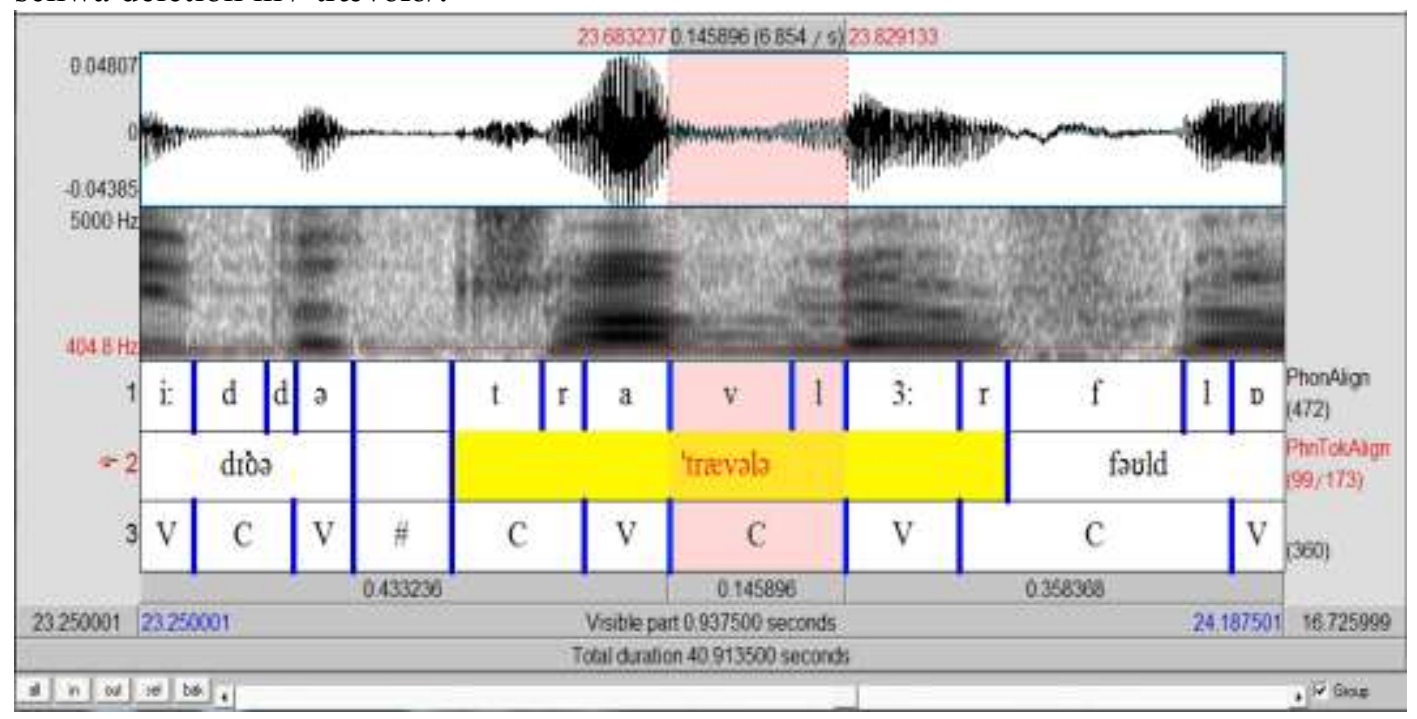

Figure 2: Example of Schwa Deletion in the word /'trævəla/

Algerian Arabic (AA) is characterised by the deletion of short vowels in open syllables that create clusters basically impermissible in Standard Arabic $/ \mathbf{J} \mathbf{b} \boldsymbol{\sigma}^{\varsigma} /$ (he is full) instead of $/ \mathbf{J a b a}^{\varsigma} \mathrm{a} /$. French also favours schwa deletion in

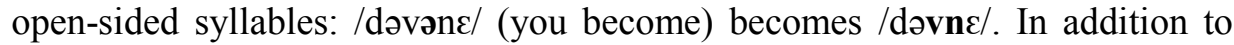
those possible interlingual sources of transfer, the informants' mispronounced words match exactly the English hierarchy of syllable structure. Glowacka (2001) and Zwicky (1972) believe that the deletion of schwa in unstressed syllables be they pre-stressed or post-stressed among native speakers of English is favoured in contexts where a resonant consonant follows it (liquid: $1, \mathrm{r}$ ), especially when it is also preceded by an obstruent (stops and fricatives: v, d). Therefore, the fact that schwa deletion exists in all the three languages known by the informants paves the way for its deletion in their interlanguage.

\subsection{2. \%V Analysis}

$\% \mathrm{~V}(44.62)$ is lower than $\Delta \mathrm{C}(63.84)$ but to some extent higher in respect to the native performance: 38.07 (in Hamdi et al. 2004) due to the addition of an epenthetic vowel /a/ or / i/ to break the final cluster that adds a non-existing syllable and thereby extra vocalic duration. This phenomenon was observed in the pronunciation of final 'ed' regular past exactly the same way as it is written: /ræpə/id/ instead of /ræpt/ (16 out of 26). However, the informants' incorrect rendition of syllable structure does not prove that the English complex syllable structure is problematic for the students under investigation. Neither the addition of an epenthetic vowel to break the two 
consonantal coda $/ \mathrm{pt} /$ in $/ \mathrm{ræpt} /$, nor the deletion of one consonant $/ \mathrm{j} /$ in the three consonantal onset $/ \mathrm{spj} / \mathrm{in} / \mathrm{di}$ 'spju:tin/ can be regarded as a simplification strategy since other complex syllable structures did not undergo such a process

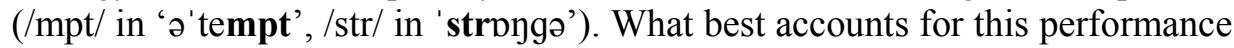
is the influence of the already orthographic systems known to the informants on their pronunciation. The Arabic phonemic orthography and the influence of French spelling on pronouncing English words of French descent contributed to the arrhythmicity of our informants' utterances.

What is also immediately observable is that the students are not sufficiently familiar with the circumstances under which function words should be reduced: they almost always use the strong forms. This is triggered off by the faulty assumption that the reduced forms are incongruous, slangy and sloppy in RP not knowing that both forms co-exist in this variety, and more importantly the weak form is the norm and the strong one is the exception. Moreover, the fact that French shares the same alphabetical system with English misguides students and results in the replacement of the weak central mid-open vowel /a/ by strong French vowels as they are more or less accustomed to the relatively consistent French spelling if compared to its English counterpart.

\begin{tabular}{|c|c|c|c|}
\hline Word & Correct Use & $\begin{array}{c}\text { Wrong } \\
\text { Use/Pronunciation }\end{array}$ & $\begin{array}{c}\text { Number of } \\
\text { Mistakes }\end{array}$ \\
\hline And & /ond/ & /ænd/ & 22 \\
\hline Were & /wa/ & /wer/, /w3:r/ & 24 \\
\hline Was & /woz/ & /wDz/- /wo:z/ & 26 \\
\hline As & $/ \partial z /$ & /æz/- /az/ & 26 \\
\hline At & /at/ & $/ æ t /-/ a t /$ & 22 \\
\hline To & $/ \mathrm{ta} /$ & $/ \mathrm{tu}: / / \mathrm{tu} /$ & 18 \\
\hline Of & /əv/ & $/ \mathrm{pv} /$ & 26 \\
\hline Should & $/ \int \partial \mathrm{d} /$ & $/ \int \mathrm{vd} /-/ \int \mathrm{u}: \mathrm{d} /$ & 24 \\
\hline
\end{tabular}

Table 3: Production of Weak Forms by Informants

Replacing schwa by full vowels is not exclusively related to function words. In fact, it expands to content words as well. If a given vowel is pronounced in its full, stressed pattern instead of being weakened to a schwa $/ \mathrm{a} /$, stress shifts from the stressed syllable to the unstressed syllable as in /'a:tempt/ or /'ætəmpt/ instead of /a'tempt/, /'ka:nfes/ or /'ko:nfes/ or /'kænfəs/ or /'kbnfəs/ instead of /kən'fes/. Furthermore, due to the inconsistent letter-tosound correspondence of English and the rather consistent spelling of French coupled with the fact that both languages share the same Latin alphabetical system, the learners tend to generalize the pronunciation of either English or French vowels to all sounds represented by the same grapheme (intralingual and interlingual transfer respectively). As a means of illustration, the learners pronounced the word 'wind' as /waind/ instead of /wind/ assuming that the 
English vowel 'i' always corresponds to the sound/aI/ in conformity with its alphabetical pronunciation. Substituting the close-mid central vowel $/ 2 /$ by either $/ \mathfrak{a} /$ or $/ \mathrm{a}: /$ in $/ \mathbf{a}$ 'tempt/ which best represents the English letter ' $\mathrm{a}$ ' in 'attempt' is another instance of intralingual transfer. As for interlingual transfer, erroneous instances are depicted in the use of the French nasal vowel

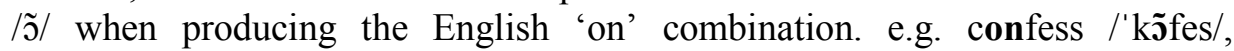
stronger /'strõgər/, and considered /'k̃̃nsidrəd/ instead of /kən' fes/, /'strongər/, $/ \mathrm{k}$ 'n'sidəd/. Another possible source of interlingual transfer resides in the origin of words. Words of Latin descent tend to take the original French pronunciation; the grapheme ' $\mathrm{o}$ ' in obliged is pronounced as the French closemid back vowel /o/: /'oblardzəd/ instead of the English schwa /a'blardzd/. As a result of generalizing the full form of vowels in unstressed syllables, the phonetic characteristics of both types of syllables, especially length, become nearly undistinguishable.

\subsubsection{Comparison of AA, AE, EN, and FR}

To best classify and thereby account for the classification of the Algerian English rhythm (henceforth AE), we need to compare this latter against the prototypical stress-timed language English (EN) along with the prototypical stress-timed language French (FR) in addition to the mother tongue of the informants, Algerian Arabic (AA). The following $\% \mathrm{~V}$ and $\Delta \mathrm{C}$ values used for comparison are taken from Hamdi et al. (2004):

\begin{tabular}{|c|c|c|}
\hline Language & Mean $\% \mathrm{~V}$ & Mean $\Delta \mathrm{C}$ \\
\hline AE & 44.62 & 63.84 \\
\hline AA & 31.14 & 57.54 \\
\hline EN & 38.07 & 75.27 \\
\hline FR & 43.38 & 48.72 \\
\hline
\end{tabular}

Table3: Mean values of $\% \mathrm{~V}$ and $\Delta \mathrm{C}$ in $\mathrm{AA}, \mathrm{AE}, \mathrm{EN}$, and FR. 


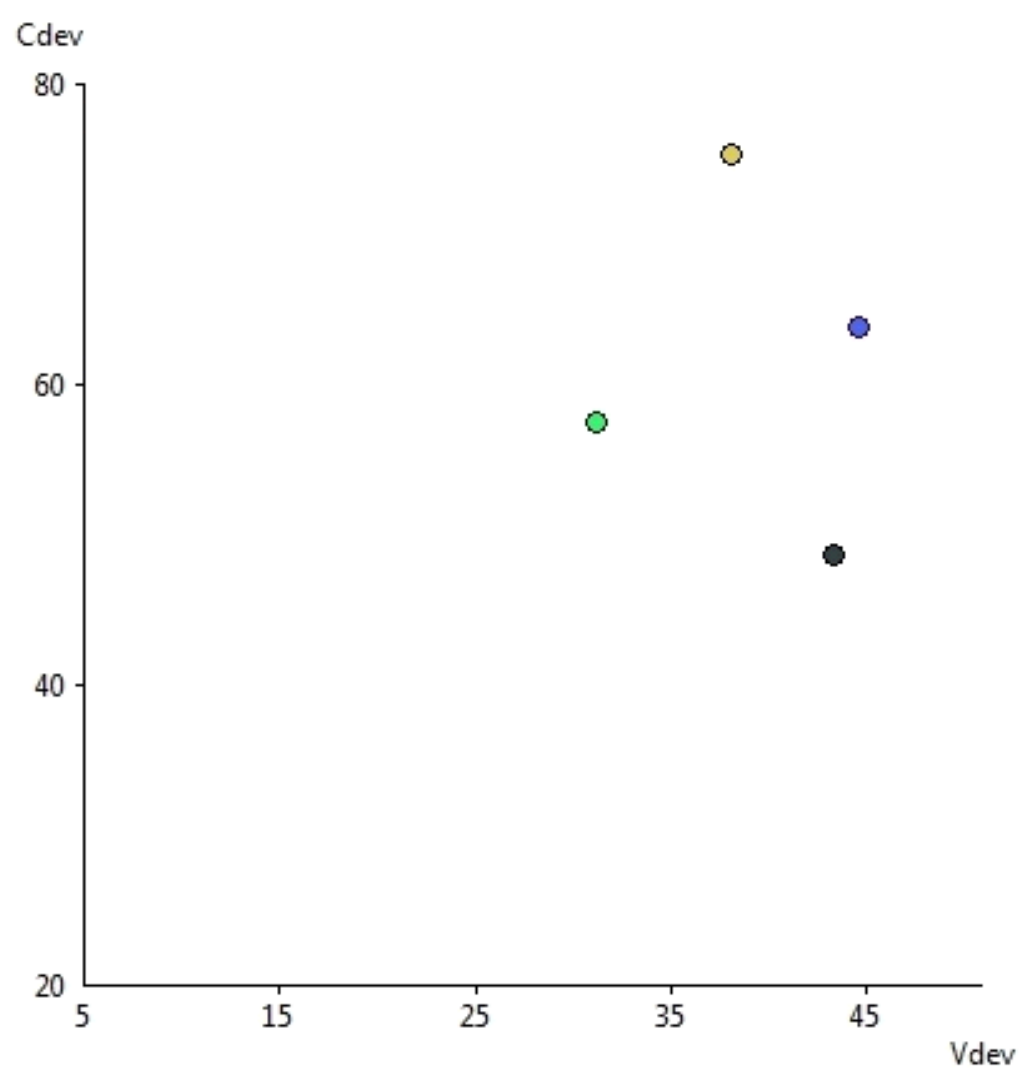

Figure 3: Comparison of $\% \mathrm{~V}$ (x axis) and $\Delta \mathrm{C}$ (y axis) in $\mathrm{AA}, \mathrm{AE}, \mathrm{EN}$, and FR.

The data presented in the above chart tallies with the researcher's justification for the deviated rhythm of the informants. The AE' $\% \mathrm{~V}$ nearly matches the one of FR than the other languages presented on the chart; conversely, the AE' $\Delta \mathrm{C}$ is closer to AA rather than FR or EN. The AE is situated somewhere between the prototypical extremes and, therefore, can be classified, according to the results of the present study, as neither a pure stresstimed language nor a discrete syllable-timed language but an intermediate language combining properties of both classes.

\section{Conclusion}

The previous analysis showed that the informants have no problems when it comes to pronounce English complex syllables. Positive transfer either from AA, as it allows consonant clusters in the onset position, or FR, as it allows up to four consonants in the onset and coda positions, might be the reason behind not using simplification strategies to ease the pronunciation of 
assumed problematic complex syllable structures of English by Arab speaking learners including Algerians, as attested by Swan and Smith (1987) and Kelly (2000).

Vowel reduction plays a great role in determining the rhythmic class to which the informants' speech rhythm belongs. The failure to produce the English mid-central unrounded vowel /a/ correctly leads to the overuse of the strong forms of function words that hold up the natural flow of speech and call for an exaggerated, unneeded energy to be spent. Besides, substituting the same vowel in content words engenders stressing unstressed syllables and/or overstressing syllables that enormously adds to the overall duration of an utterance and, substantially, permeates the overall rhythm. Accordingly, to master an English-like speech rhythm, more focus should be put on the pronunciation of vocalic segments especially the mid-central unrounded vowel $/ \mathrm{a} /$ in order to get a lower $\% \mathrm{~V}$ and a higher $\Delta \mathrm{C}$, a common property of stresstimed languages.

\section{References}

Abercormbie, D. (1967). Elements of General Phonetics. Edinburgh University Press.

Barry, W. J., Andreeva, B., Russo, M., Dimitrova, S., \& Kostadinova, T. (2003). Do rhythm measures tell us anything about language type? In M. J. Solé, D. Recasens, \& J. Romero (Eds.), Proceedings of the 15th International Congress of Phonetic Sciences (pp. 2693-2696). Barcelona: Casual Productions.

Dauer, R .M. (1983). Stress-timing and syllable-timing reanalysed, Journal of Phonetics 11, pp 51-69.

Dauer, R.M., (1987). Phonetic and phonological components of language rhythm. In Proceedings of the XIth ICPhS, Tallinn, Estonia, pp. 447-450.

Dellwo, V., \& Wagner, P. (2003). Relations between language rhythm and speech rate. In M. J. Solé, D. Recasens, \& J. Romero (Eds.), Proceedings of the 15th International Congress of Phonetic Sciences (pp. 471-474). Barcelona: Casual Productions.

Ghazali, S., Hamdi, R. \& Barkat-Defradas, M. (2002). Speech Rhythm variation in Arabic dialects. In proceedings of the $1{ }^{\text {st }}$ international Conference on Speech Prosody, Aix-en-Provence, pp. 331-334.

Glowacka, D. (2001). Unstressed vowel deletion and new consonant clusters in English. Poznan Studies in Contemporary Linguistics 37, pp.71-94.

Grabe, E. \& Low, E. L. 2002. Durational variability in speech and the rhythm class hypothesis. Papers in Laboratory Phonology 7, pp. 515-546. 
Hamdi, R. Barkat-Defradas, M., Ferragne, E. and Pellegrino, F. (2004). Speech timing and rhythmic structure in Arabic dialects: A comparison of two approaches, in Proc. Interspeech, Lisbon, Portugal.

Kelly, G. (2000). How to Teach Pronunciation. Pearson Education Limited. Laver, John. (1994). Principles of Phonetics. United Kingdom: CUP. Mairano, P. (2011). Rhythm typology: studies in acoustics and perception. (Doctoral dissertation). Retrieved from tel.archives-ouvertes.fr. (Accession Order No. tel-00654261, version 1)

Patel, Aniruddh D. (2008), Music, language, and the brain (p. 120). New York: Oxford university press.

Pike, K. (1945). The Intonation of American English (pp. 34, 35). Ann Arbor: University of Michigan Press.

Ramus, F., Nespor, M. \& Melher, J. (1999). Language identification with suprasegmental cues. A study based on speech resynthesis. Journal of the acoustical Society of America, 105(1), pp. 512-521.

Roach, P. (1982). On the distinction between 'stress-timed' and 'syllable-timed' languages. In David Crystal (Ed.), Linguistic controversies (pp. 73-79). London: Edward Arnold.

Swan, M., \& Smith, B. (1987). Learner English. Cambridge: Cambridge University Press.

Zwicky, A., 1972. Note on a phonological hierarchy of English. In R. Stockwell \& R. Macaulay (Eds.), Linguistic change and generative theory (pp. 275-301). Bloomington, IN: Indiana University Press.

Note :

1-A story used in the Handbook of the International Phonetic Association as a sample to represent all phonemic contrasts in English when testing foreign language learners. 